\title{
Simultaneous Determination of Rare Earth Elements in Aqueous Samples by Online Preconcentration System and Inductively Coupled Plasma Mass Spectrometry
}

\author{
Zhu Xuxua, Lin Jianjie ${ }^{\mathrm{b}}$, Gao Aiguo ${ }^{\mathrm{a}} \mathrm{c}^{*}$, Wang Danhongd, and Zhu Min ${ }^{\mathrm{e}}$ \\ ${ }^{a}$ College of Ocean and Earth Sciences, Xiamen University, Xiamen 361102, P.R. China \\ b Marine and Fisheries Technology Center of Fuzhou, Fuzhou 350026, P.R. China \\ c State Key Laboratory of Marine Environmental Sciences, Xiamen 361102, P.R. China \\ d Inspection and Quarantine Center of Fujian Entry-Exit Inspection and Quarantine Bureau, Fujian \\ Province Key Laboratory of Inspection and Quarantine Technology Research, Fuzhou 350003, P.R. China \\ e PerkinElmer Management (Shanghai) Co., Ltd, Shanghai 201203, P.R. China
}

\begin{abstract}
Rare earth elements (REEs) are useful geological tracers, however, their extremely low concentrations (ng/L or lower) and high salt matrix make their measurement a challenge. In this sutdy, an online preconcentration system, which uses a PA-1 mixed resin with ethylenediaminetriacetic acid and iminodiacetic acid functional groups, coupled with a seaFAST autosampler and inductively coupled plasma mass spectrometry (ICP-MS), is used to determine REEs in aqueous samples. The process of the system is automatic, the concentrated samples are directly injected into the nebulizer of the ICP-MS, while the alkali and alkaline earth elements are washed out. The linearity coefficients of the REEs were in the range of 0.99967 (Ce) to 0.99999 (Eu, Gd, Tm), procedural blank values ranged from $0.002 \mathrm{ng} / \mathrm{L}$ (Tm) to $0.426 \mathrm{ng} / \mathrm{L}$ $(\mathrm{Ce})$, and the DLs $(3 \sigma)$ were found in the range of $0.007 \mathrm{ng} / \mathrm{L}$ (Tm) to $0.250 \mathrm{ng} / \mathrm{L}(\mathrm{Ce})$. The reproducibilities, obtained from 17 aliquots of $500 \mathrm{ng} / \mathrm{L}$ diluted
\end{abstract}

REE standard solutions acidified to $\mathrm{pH} 2$, were from $1.38-3.56 \%$. The accuracy was demonstrated by measurement of three NRC (National Research Council of Canada) reference materials of SLEW-3, CASS-4, and NASS-6. The results suggested that the REE concentrations and PAAS normalized patterns of the three CRMs were consistent with those from previous researchers. The REE spike recovery was assessed with NRC CRMs and brackish water collected from the Minjiang Estuary. The recovery values of SLEW3 , CASS- 4 , and NASS- 6 were in the range of $92.7 \%(\mathrm{~Tb})-104.5 \%$ (La), 91.6\% (Ho)-111.9\% (La), $95.1 \%(\mathrm{Nd})-118.3 \%(\mathrm{Ce})$, respectively. The recovery values obtained from the brackish waters were good at various salinities (96.0-107.4\%), illustrating that the matrix effects could be ignored with this method. The REE patterns of surface waters from the Minjiang Estuary show seaward HREEs enriched and slightly negative Ce anomalies. Besides, Gd positive anomalies were present in Minjiang River waters.

\section{INTRODUCTION}

Rare earth elements (REEs) generally serve as useful geological tracers due to their systematic variation in chemical properties and the varying oxidation states of $\mathrm{Ce}$ and

\footnotetext{
*Corresponding autbor.

E-mail:aggao@xmu.edu.cn

Tel: 8618250878289
}

Eu (1-4). The demand for REE measurements is increasing due to their potentially wide applications, while the accurate measurement of REEs in natural waters is still challenging because of their extremely low concentrations (ng/L or lower) and the high salt matrix. The salt matrix would lead to analytical interferences and severe instrumental conditions, such as polyatomic mass spectral interferences, instrumental drift, signal suppression, and clogging of the sample introduction system of the instrument $(5,6)$. Particularly, the different extent of matrix effects in natural waters with various salinities, such as in estuarine waters, is too complicated to accurately quantify (7).

In early research, neutron activation analysis (NAA) and isotope dilution thermal ionization mass spectrometry (ID-TIMS) were commonly used to measure REEs. However, these methods were phased out because they are time-consuming, laborious, and require sophisticated operation, large sample sizes, and high cost $(8,9)$. In the 1990s, the application of inductively coupled plasma mass spectrometry (ICP-MS) provided an alternative and reliable approach for the precise determination of REEs in various matrices because of high sensitivity, high selectivity, and high sample throughput. The matrix effects, however, are serious problems in ICP-MS (8). Therefore, the pre-concentration and separation of REEs from natural waters are indispensible.

The batch pre-concentration methods include liquid-liquid extraction (10-12), co-precipitation as oxides (13-15), ion exchange resins $(16,17)$ and chelating resins (7). Among these, solid-phase extraction with chelating resins is recognized as one of the most effective approaches for matrix removal and pre-concentration (7). Examples include NTA complexation, 8 HQ $(18,19)$, and iminodiacetic 
acid (IDA)-type resins such as Chelex-100, Muromac A-1, Toyopearl AF-Chelate-650M, and Metpac CC-1 (20, 21). However, many of these resins have a relatively high affinity for alkalineearth elements and a narrow operating $\mathrm{pH}$ range for complexation $(7,22,23)$. It should be mentioned that the new dual-functionalized resin Nobias Chelate-PA1, which consists of ethylenediamine triacetic acid (EDTriA) and IDA, has extremely low retention of alkalineearth elements and a relatively wide working $\mathrm{pH}$. It has been utilized worldwide and efficiently applied for the determination of REEs and transition metals in natural waters $(7,24-27)$.

The batch pre-treatment methods are limited in that they are time-consuming and often show discrepancies in the analytical results due to lack of operator skill. However, the on-line pre-treatment methods have become the preferred pre-concentration methods because they require small sample volume, offer good accuracy and reproducibility, and result in low airborne contamination $(8,18,19,28,29)$.

The seaFAST Tм (Elemental Scientific, Inc., USA) on-line pre-concentration system, which uses a Nobias Chelate-PA1 resin, can pre-concentrate the target elements and remove the salt matrix. Previous studies support the applicability of seaFAST-ICP-MS in the analysis of trace and ultratrace elements, such as $\mathrm{Fe}, \mathrm{Cu}, \mathrm{Co}, \mathrm{Mn}, \mathrm{Zn}, \mathrm{Ti}, \mathrm{Zr}, \mathrm{Nb}$, Mo, V, and W $(24,29)$. Hathorne et al. (30) have determined REEs in seawater using the older version of seaFAST which utilizes a peristaltic pump with ICP-MS. For the present study, the improved version named seaFAST S2, which uses syringe pumps instead of peristaltic pumps, was used because it guarantees more precise injection volumes of the samples and reagents and, therefore, more accurate measure- ments. The excellent utility and performance of seaFAST S2 with ICP-MS is demonstrated through the analysis of the certified reference materials (CRMs) SLEW-3, CASS- 5 and NASS- 6 from the National Research Council of Canada (NRC). Furthermore, the ability to remove the salt matrix using this method is validated through the analysis of estuarine waters at various salinities (0-26\%o) collected in the Minjiang River, southeastern China.

\section{EXPERIMENTAL}

\section{Standard Solutions, Reagents, and Materials}

REE standard solutions were prepared from 1000 mg/L GSB04-17892004 REEs standard solutions (General Research Institute for Nonferrous Metals of Beijing, P.R. China). High purity reagents, $\mathrm{HNO}_{3}$ (Merck, Germany) and acetic acid and ammonia (Fisher Scientific, USA), were used for solution preparation, instrumental processes, and sample analysis. Milli-Q ${ }^{\circledR}$ water (MQW, 18.2 M $\Omega-c m$, Millipore Corporation, USA) was used during the course of this study. An ammonium acetate buffer was prepared by adding $280 \mathrm{~mL}$ of concentrated acetic acid (100\%, v:v) and $280 \mathrm{~mL}$ of concentrated ammonia (29\%, $\mathrm{v}: \mathrm{v})$ to Milli-Q water to a final volume of $1000 \mathrm{~mL}$. The $\mathrm{pH}$ of the ammonium acetate buffer was adjusted to $6.0 \pm 0.2$ with ammonium. Nitric acid (10\%, v:v) was prepared by adding $50 \mathrm{~mL}$ concentrated nitric acid to Milli-Q water to a final volume of $500 \mathrm{~mL}$ in a polyethylene (LDPE) bottle and used as the eluent. In addition, three certified reference materials SLEW-3, CASS-4, NASS-6 (all from the National Research Council of Canada), were used for method validation. Although there were no certified values for these reference materials, the literature values have been obtained by many other methods. There have been fewer studies on NASS-6 than on NASS-5, and the inter-laboratory comparisons of NASS- 6 are relatively few. However, NASS-6 replaces NASS-5, which is no longer commercially available. Thus, NASS6 was chosen for this work in the hope that the concentrations of NASS-6 obtained will be accepted by the peers. The estuarine waters, with salinities ranging from $0.1 \%$ o to $26.0 \%$, were collected from Minjiang Estuary $\left(119.46^{\circ} \sim\right.$ $\left.119.73^{\circ} \mathrm{N}, 25.97^{\circ} \sim 26.25^{\circ} \mathrm{E}\right)$, which is the largest mountainous river of southeastern China during the high flood season.

Reagents and samples were prepared and stored in low density polyethylene (LDPE) bottles (Nalgene, USA) or polypropylene tubes (Nunc, USA), and the standard solutions were stored in Teflon ${ }^{\circledR}$ fluorinated ethylene propylene (FEP) bottles (Nalgene, USA). All bottles and tubes were soaked overnight in 4M nitric acid (analytical purity) and rinsed with deionized water (DIW). Subsequently, they were filled with DIW, left standing on an ultrasonic cleaner for 1 hour and then emptied; this procedure was repeated twice. The bottles and tubes were then rinsed with MQW and air-dried in a fume hood.

\section{Online Pre-concentration Method}

The seaFAST $\mathrm{S} 2$ system, which uses PA-1 mixed resin (Hitachi, Japan) with the ethylenediaminetriacetic acid and iminodiacetic acid functional groups, is commercially available. The system includes a seaFAST auto-sampler (SC-2/4DX), a seawater preconcentration column (part number CF-N-0200, ESI), a trace metals cleanup column (CF-M0600), four syringe pumps (S400V), and two inert 6-port valves (Figure 1).

With the integrated vacuum pump of the seaFAST autosampler, the $4.0 \mathrm{~mL}$ sample loop and buffer loop are rinsed and filled with sample 
and buffer, respectively. The actual usage volume of the sample is $\sim 7$ $\mathrm{mL}$ to allow for rinsing and overfilling of the loop. Meanwhile, a flow of $10 \%$ nitric acid was passed through the spray chamber of the ICP-MS to rinse the injection system. A continuous flow of ammonium acetate was passed through the seawater preconcentration column to maintain a $\mathrm{pH}$ of 6 . The sample and buffer pass through the trace metal cleanup column and mix before injecting into the seawater preconcentration column. Subsequently, the sample is loaded and the target elements in the sample are chelated onto the column, while the alkali and alkaline earth elements are washed out by the carrier. Meanwhile, the preconcentration column is reverse-flushed with a flow of $10 \%$ nitric acid, and the target elements are eluted into the nitric acid. Then, the elution acid is directly injected into the nebulizer of the ICP-MS. The above automated sequence requires a total of $8 \mathrm{~min}$ utes 48 seconds to complete.
Finally, the syringe pushes another mixed flow of $10 \%$ nitric acid and buffer onto the column to condition it for the next analysis.

\section{ICP-MS Conditions}

A NexION $^{\circledR}$ 300D ICP-MS

(PerkinElmer Inc, Shelton, CT, USA) was used for the determination of REEs in this study. The instrumental operating conditions are listed in Table I.

For this study, the standard mode of the ICP-MS was used for the determination of ${ }^{139} \mathrm{La},{ }^{140} \mathrm{Ce}$, ${ }^{141} \mathrm{Pr},{ }^{146} \mathrm{Nd},{ }^{147} \mathrm{Sm},{ }^{153} \mathrm{Eu},{ }^{157} \mathrm{Gd}$, ${ }^{159} \mathrm{~Tb},{ }^{163} \mathrm{Dy},{ }^{165} \mathrm{Ho},{ }^{166} \mathrm{Er},{ }^{169} \mathrm{Tm}$, ${ }^{172} \mathrm{Yb}$, and ${ }^{175} \mathrm{Lu}$. The elution acid with the target elements was injected into the spray chamber of the ICP-MS through a concentric glass Meinhard ${ }^{\circledR}$ nebulizer and quartz ball joint injector $(2.0 \mathrm{~mm}$ i.d.).

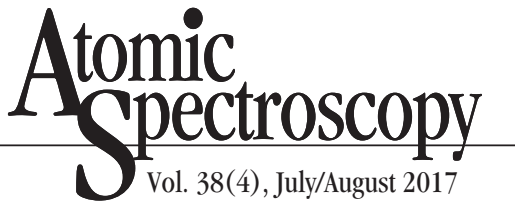

\section{RESULTS AND DISCUSSION}

\section{Procedural Blanks and Detection Limits}

Procedural blanks include the blanks from the reagents, pretreatment, and ICP-MS analysis (see Table II). They were determined by applying the seaFAST-ICP-MS procedure to 11 aliquots of Milli-Q water that were acidified to $\mathrm{pH} 2$ by adding concentrated nitric acid. In order to represent the procedural blank in accordance with the samples, separately prepared blank samples were analyzed during each experimental batch. The detection limits (DLs) were based on three times the standard deviation of 11 different aliquots of the calibration blank. The calibration curve was made up from 1, 10, 50, 100, 300, and $500 \mathrm{ng} / \mathrm{L}$ standards.

Calibration standards show excellent linearity. The linearity coefficients $(R)$ of the REEs were in the range of 0.99967 for Ce to

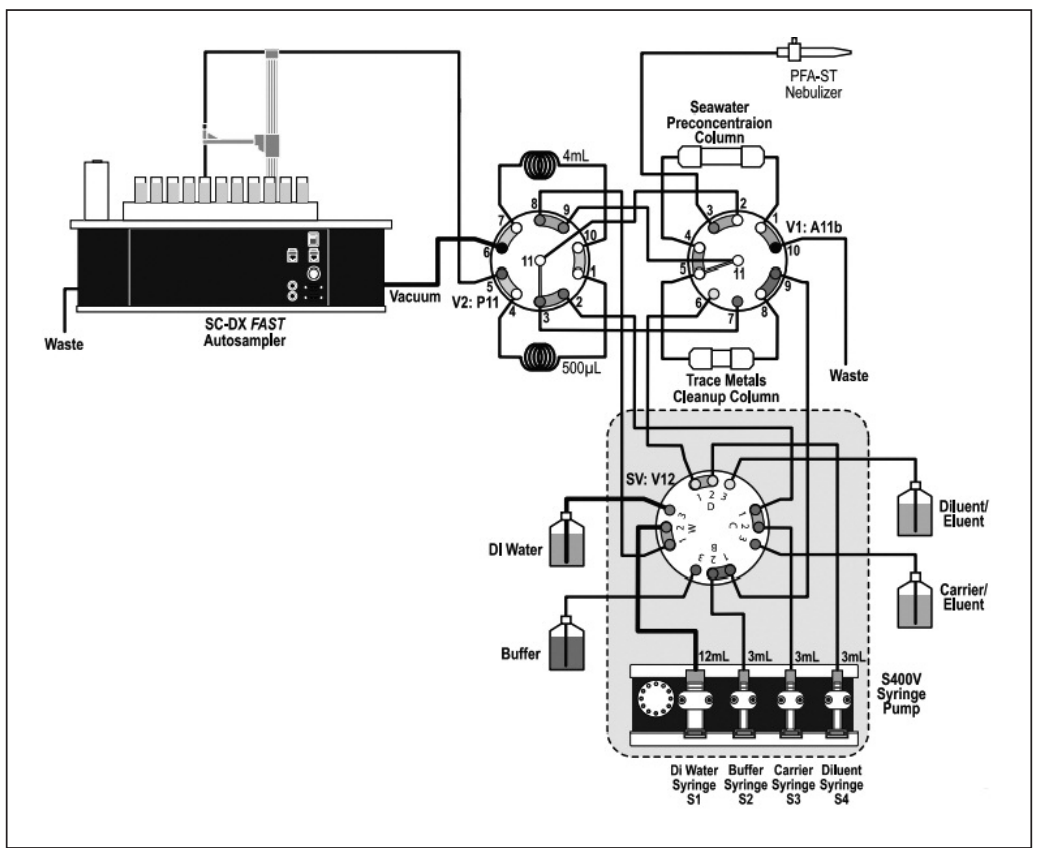

Fig. 1. The schematic configuration of the seaFAST S2 preconcentration system (from the seaFAST 22 method guide of Elemental Scientific Inc.).
TABLE I ICP-MS Instrumental Operating Conditions

\begin{tabular}{ll}
\hline Parameters & Operating Conditions \\
\hline ICP RF power & $1100 \mathrm{~W}$ \\
Nebulizer gas flow & $0.84 \mathrm{~L} / \mathrm{min}$ \\
Auxiliary gas flow & $1.2 \mathrm{~L} / \mathrm{min}$ \\
Plasma gas flow & $15 \mathrm{~L} / \mathrm{min}$ \\
Nebulizer & Concentric glass \\
& Meinhard nebulizer \\
& for $500 \mu \mathrm{L} / \mathrm{min}$ \\
Spray chamber & Baffled glass cyclonic \\
& spray chamber O-ring-free \\
Sweep & 4 \\
Reading & 27 \\
Replicates & 1 \\
Dwell time & $35 \mathrm{~ms}$ \\
Estimated time & $129 \mathrm{~s}$ \\
Sample uptake rate & $0.5 \mathrm{~mL} / \mathrm{min}$ \\
Pass & 4 \\
Run & 27 \\
Scan (Pass $\times$ Run) & 108 \\
\hline
\end{tabular}


0.99999 for $\mathrm{Eu}, \mathrm{Gd}$, and Tm (Table II), which are better than the linearity coefficients measured by other preconcentration methods [Kajiya et al. (19) and Raso et al. (6)]. The blank values ranged from 0.002 $\mathrm{ng} / \mathrm{L}$ for Tm to $0.426 \mathrm{ng} / \mathrm{L}$ for Ce. The standard deviations were in the range of $0.002 \mathrm{ng} / \mathrm{L}$ for Tm to 0.083 $\mathrm{ng} / \mathrm{L}$ for Ce. The DLs $(3 \sigma)$ were found in the range of $0.007 \mathrm{ng} / \mathrm{L}$ for Tm to $0.250 \mathrm{ng} / \mathrm{L}$ for Ce. The blank values, standard deviations, and DLs were slightly better than those of Hathorne et al. (30), which also used the seaFAST-ICP-MS method. The low blank and DLs highlight the good performance of this method and, therefore, the performance of this method is suitable for high quality measurement of ultratrace REEs in natural waters.

\section{Reproducibility and Accuracy}

To assess the reproducibility of the method, 17 aliquots of REE standard solutions were diluted gravimetrically to $500 \mathrm{ng} / \mathrm{L}$ with Milli-Q water, acidified to $\mathrm{pH} 2$ with concentrated nitric acid, and measured as unknown samples during each experimental batch, spanning a 4-month period. The results indicated that the precision is $1.38 \%$ (Ho) $-3.56 \%$ (Ce) for all REEs. The precision of this study is obviously better than that of Hathorne et al. (30) (1s, 3.1-11.1\%), which is obtained by the analysis of circumpolar deep water from the Southern Ocean. That may be partly due to the different pumps used in the experiment. The syringe pump used in the present study guarantees a more precise injection volume of the samples and, therefore, better precision than with the peristalitic pumps.

The accuracy of the methodology was validated by using three natural water CRMs SLEW-3, CASS5, and NASS-6. For the purpose of obtaining the long-term mean values and standard deviations of

TABLE II

Procedural Blank, Linearity Coefficient, Standard Deviation, and Detection Limit

\begin{tabular}{ccccccc}
\hline Element & $\mathrm{m} / \mathrm{z}$ & $\begin{array}{c}\text { Linearity } \\
\text { Coefficient }\end{array}$ & $\begin{array}{c}\text { Procedural } \\
\text { Blank }^{\mathrm{a}} \\
(\mathrm{ng} / \mathrm{L})\end{array}$ & $\begin{array}{c}\text { Standard } \\
\text { Deviation } \\
(\mathrm{ng} / \mathrm{L})\end{array}$ & $\begin{array}{c}\text { Detection } \\
\text { Limit }^{\mathrm{b}} \\
(\mathrm{ng} / \mathrm{L})\end{array}$ & RSD $^{\mathrm{c}}$ \\
\hline $\mathrm{La}$ & 139 & 0.99996 & 0.327 & 0.068 & 0.205 & 2.54 \\
$\mathrm{Ce}$ & 140 & 0.99967 & 0.426 & 0.083 & 0.250 & 3.56 \\
$\mathrm{Pr}$ & 141 & 0.99975 & 0.056 & 0.015 & 0.045 & 2.57 \\
$\mathrm{Nd}$ & 143 & 0.99988 & 0.263 & 0.054 & 0.161 & 2.58 \\
$\mathrm{Sm}$ & 147 & 0.99998 & 0.034 & 0.027 & 0.082 & 1.88 \\
$\mathrm{Eu}$ & 153 & 0.99999 & 0.008 & 0.005 & 0.015 & 1.96 \\
$\mathrm{Gd}$ & 157 & 0.99999 & 0.052 & 0.014 & 0.043 & 2.72 \\
$\mathrm{~Tb}$ & 159 & 0.99994 & 0.006 & 0.003 & 0.010 & 1.97 \\
$\mathrm{Dy}$ & 163 & 0.99987 & 0.034 & 0.021 & 0.062 & 1.44 \\
$\mathrm{Ho}$ & 165 & 0.99985 & 0.010 & 0.006 & 0.017 & 1.38 \\
$\mathrm{Er}$ & 166 & 0.99993 & 0.029 & 0.021 & 0.063 & 2.06 \\
$\mathrm{Tm}$ & 169 & 0.99999 & 0.002 & 0.002 & 0.007 & 1.93 \\
Yb & 172 & 0.99998 & 0.010 & 0.005 & 0.014 & 1.56 \\
Lu & 175 & 0.99998 & 0.003 & 0.003 & 0.009 & 1.72 \\
\hline
\end{tabular}




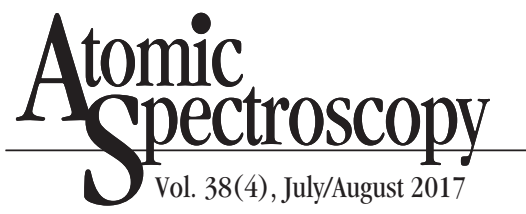

TABLE III

REE Concentrations (ng/L) of SLEW-3 and NASS-6 With Quoted Uncertainty (based on long-term reproducibility of SLEW-3 and NASS-6) and Literature Data

\begin{tabular}{lcccc|ccc}
\hline & \multicolumn{5}{c}{ SLEW-3 } & \multicolumn{3}{c}{ NASS-6 } \\
\hline & This work & $\begin{array}{c}\text { Lawrence and } \\
\text { Kamber (31) }\end{array}$ & $\begin{array}{c}\text { Bayonet al. } \\
(32)\end{array}$ & $\begin{array}{c}\text { Wang et al. } \\
(7)\end{array}$ & This work & \multicolumn{2}{c}{ Raso et al. } \\
$(6)$ & $\begin{array}{c}\text { Wang et al. } \\
(7)\end{array}$ \\
\hline $\mathrm{La}$ & $8.00 \pm 1.00$ & $7.89 \pm 0.92$ & $7.63 \pm 0.83$ & $8.61 \pm 0.83$ & $11.82 \pm 0.62$ & $12.70 \pm 0.80$ & $10.70 \pm 1.25$ \\
$\mathrm{Ce}$ & $7.03 \pm 0.72$ & $7.56 \pm 1.74$ & $6.58 \pm 0.56$ & $7.14 \pm 0.56$ & $6.35 \pm 0.49$ & $6.20 \pm 0.60$ & $4.48 \pm 0.84$ \\
$\mathrm{Pr}$ & $1.69 \pm 0.22$ & $1.71 \pm 0.16$ & $1.69 \pm 0.14$ & $1.69 \pm 0.14$ & $1.83 \pm 0.14$ & $2.00 \pm 4.00$ & $1.69 \pm 0.28$ \\
$\mathrm{Nd}$ & $8.34 \pm 0.68$ & $8.42 \pm 1.78$ & $7.93 \pm 0.29$ & $8.21 \pm 1.30$ & $7.84 \pm 0.36$ & $6.00 \pm 6.00$ & $6.78 \pm 1.15$ \\
$\mathrm{Sm}$ & $7.54 \pm 0.68$ & $6.99 \pm 0.74$ & $7.21 \pm 0.06$ & $7.52 \pm 0.60$ & $1.42 \pm 0.10$ & $0.80 \pm 0.14$ & $1.35 \pm 0.15$ \\
$\mathrm{Eu}$ & $0.56 \pm 0.04$ & $0.60 \pm 0.38$ & $0.45 \pm 0.03$ & $0.53 \pm 0.02$ & $0.27 \pm 0.07$ & $0.24 \pm 0.08$ & $0.27 \pm 0.03$ \\
$\mathrm{Gd}$ & $3.30 \pm 0.26$ & $3.08 \pm 0.60$ & $3.14 \pm 0.47$ & $3.14 \pm 0.16$ & $1.85 \pm 0.08$ & $1.00 \pm 4.00$ & $1.34 \pm 0.28$ \\
$\mathrm{~Tb}$ & $0.47 \pm 0.04$ & $0.45 \pm 0.12$ & $0.46 \pm 0.03$ & $0.49 \pm 0.02$ & $0.26 \pm 0.05$ & $0.20 \pm 0.40$ & $0.24 \pm 0.10$ \\
$\mathrm{Dy}$ & $3.43 \pm 0.48$ & $3.35 \pm 0.76$ & $3.41 \pm 0.16$ & $3.57 \pm 0.16$ & $1.80 \pm 0.08$ & $1.60 \pm 0.40$ & $1.63 \pm 0.16$ \\
$\mathrm{Ho}$ & $0.90 \pm 0.10$ & $0.91 \pm 0.26$ & $0.98 \pm 0.03$ & $0.89 \pm 0.07$ & $0.45 \pm 0.06$ & $0.31 \pm 0.04$ & $0.40 \pm 0.12$ \\
$\mathrm{Er}$ & $2.82 \pm 0.30$ & $2.72 \pm 0.72$ & $2.67 \pm 0.17$ & $2.50 \pm 0.17$ & $1.47 \pm 0.16$ & $1.70 \pm 0.60$ & $1.34 \pm 0.17$ \\
$\mathrm{Tm}$ & $0.36 \pm 0.06$ & $0.37 \pm 0.14$ & - & $0.30 \pm 0.05$ & $0.21 \pm 0.05$ & $0.24 \pm 0.18$ & $0.19 \pm 0.05$ \\
$\mathrm{Yb}$ & $1.86 \pm 0.20$ & $2.05 \pm 1.08$ & $1.90 \pm 0.17$ & $2.07 \pm 0.52$ & $1.40 \pm 0.14$ & $1.30 \pm 0.40$ & $1.31 \pm 0.28$ \\
$\mathrm{Lu}$ & $0.33 \pm 0.12$ & $0.33 \pm 0.22$ & $0.30 \pm 0.02$ & $0.31 \pm 0.18$ & $0.24 \pm 0.07$ & $0.26 \pm 0.08$ & $0.21 \pm 0.07$ \\
\hline $\mathrm{V}$
\end{tabular}

Values: mean $\pm 2 S D$.

TABLE IV

REE Concentrations (ng/L) of CASS- 4 With Quoted Uncertainty (based on the long-term reproducibility of CASS-4) and Literature Data

\begin{tabular}{lccccccc}
\hline CASS-4 & This work & $\begin{array}{c}\text { Zhu et al. } \\
(17)\end{array}$ & $\begin{array}{c}\text { Zhu et al. } \\
(5)\end{array}$ & $\begin{array}{c}\text { Lawrence and } \\
\text { Kamber }(31)\end{array}$ & $\begin{array}{c}\text { Freslon et al. } \\
(33)\end{array}$ & $\begin{array}{c}\text { Bayon et al. } \\
(32)\end{array}$ & $\begin{array}{c}\text { Zheng et al. } \\
(9)\end{array}$ \\
\hline $\mathrm{La}$ & $9.58 \pm 0.15$ & $8.70 \pm 1.00$ & $10.00 \pm 0.80$ & $9.34 \pm 0.96$ & $9.00 \pm 1.40$ & $9.30 \pm 0.40$ & $9.20 \pm 0.60$ \\
$\mathrm{Ce}$ & $5.39 \pm 0.20$ & $4.20 \pm 0.60$ & $6.10 \pm 0.60$ & $4.62 \pm 1.88$ & $3.80 \pm 0.20$ & $3.85 \pm 0.06$ & $4.30 \pm 0.80$ \\
$\mathrm{Pr}$ & $1.43 \pm 0.05$ & $1.34 \pm 0.14$ & $1.42 \pm 0.08$ & $1.41 \pm 0.18$ & $1.27 \pm 0.12$ & $1.311 \pm 0.01$ & $1.32 \pm 0.08$ \\
$\mathrm{Nd}$ & $6.16 \pm 0.32$ & $5.8 \pm 1.20$ & $5.50 \pm 1.00$ & $6.03 \pm 1.08$ & $5.60 \pm 0.80$ & $5.51 \pm 0.10$ & $4.70 \pm 0.20$ \\
$\mathrm{Sm}$ & $5.48 \pm 0.12$ & $5.4 \pm 0.60$ & $5.50 \pm 1.00$ & $5.73 \pm 0.48$ & $5.60 \pm 0.60$ & $5.73 \pm 0.08$ & $5.30 \pm 0.40$ \\
$\mathrm{Eu}$ & $0.22 \pm 0.03$ & $0.25 \pm 0.06$ & $0.19 \pm 0.06$ & $0.24 \pm 0.02$ & $0.23 \pm 0.06$ & $0.21 \pm 0.04$ & $0.23 \pm 0.01$ \\
$\mathrm{Gd}$ & $1.48 \pm 0.12$ & $1.50 \pm 0.20$ & $1.40 \pm 0.40$ & $1.34 \pm 0.18$ & $1.31 \pm 0.18$ & $1.34 \pm 0.12$ & $1.12 \pm 0.06$ \\
$\mathrm{~Tb}$ & $0.21 \pm 0.05$ & $0.19 \pm 0.02$ & $0.17 \pm 0.06$ & $0.21 \pm 0.02$ & $0.19 \pm 0.04$ & $0.189 \pm 0.02$ & $0.17 \pm 0.01$ \\
$\mathrm{Dy}$ & $1.38 \pm 0.13$ & $1.20 \pm 0.20$ & $1.50 \pm 0.40$ & $1.49 \pm 0.14$ & $1.40 \pm 0.20$ & $1.39 \pm 0.08$ & $1.28 \pm 0.08$ \\
$\mathrm{Ho}$ & $0.37 \pm 0.05$ & $0.38 \pm 0.08$ & $0.35 \pm 0.06$ & $0.41 \pm 0.08$ & $0.36 \pm 0.06$ & $0.368 \pm 0.02$ & $0.34 \pm 0.02$ \\
$\mathrm{Er}$ & $1.23 \pm 0.07$ & $1.12 \pm 0.20$ & $1.10 \pm 0.20$ & $1.38 \pm 0.24$ & $1.18 \pm 0.12$ & $1.202 \pm 0.02$ & $1.11 \pm 0.06$ \\
$\mathrm{Tm}$ & $0.17 \pm 0.03$ & - & $0.20 \pm 0.10$ & $0.22 \pm 0.06$ & - & - & $0.16 \pm 0.01$ \\
$\mathrm{Yb}$ & $1.17 \pm 0.06$ & $1.30 \pm 0.20$ & $1.20 \pm 0.40$ & $1.43 \pm 0.80$ & $1.09 \pm 0.14$ & $1.15 \pm 0.04$ & $1.06 \pm 0.06$ \\
$\mathrm{Lu}$ & $0.20 \pm 0.03$ & $0.20 \pm 0.06$ & $0.16 \pm 0.06$ & $0.25 \pm 0.16$ & $0.19 \pm 0.02$ & $0.184 \pm 0.004$ & $0.18 \pm 0.01$ \\
\hline
\end{tabular}

Values: mean $\pm 2 S D$.

work discussed above. Previous researchers have reported that examinations of NRC CRMs, such as CASS-2, CASS-3, NASS-4, NASS-5 and SLEW-3, reveal that the Sm over-abundance is present in all of these reference materials due to the contamination during reference materials preparation $(20,31,36)$. Considering that NASS- 6 is the lat- est product of NRC, it is probable that NASS-6 was not affected by the contamination. Although NASS-6 has been commercially available for a few years, studies addressing this 
issue have not been done. The NASS-6 values measured in the present work could provide another reference value for researchers.

\section{Recovery}

In order to evaluate the accuracy of the entire procedure, the spike recoveries were determined by REE-spiked NRC CRM solutions. A 10-ng/L amount of REE spikes was added to SLEW-3, CASS-4, and NASS-6. The recovery was calculated as the ratio between analyzed and spiked concentrations for each element ( $\mathrm{n}=5$ for the NRC CRM solutions).
The recovery values of the NRC reference materials show excellent performance with good repeatability (from $1.0 \%$ for Dy to $6.3 \%$ for Er). The recovery values of SLEW-3 were from $92.7 \%$ for $\mathrm{Tb}$ to $104.5 \%$ for La, and those of CASS- 4 and NASS-6 were relatively slightly higher: in the ranges of $91.6 \%$ for Ho to $111.9 \%$ for $\mathrm{La}$, and of $95.1 \%$ for Nd to $118.3 \%$ for Ce (as shown in Table V), respectively. The recovery values are comparable and even slightly better than the values (75\%-108\% and 88\%-117\%) obtained by the research of Raso et al. (6) in which the REE spikes of $20 \mathrm{ng} / \mathrm{L}$ were added into two seawater solutions. However, they

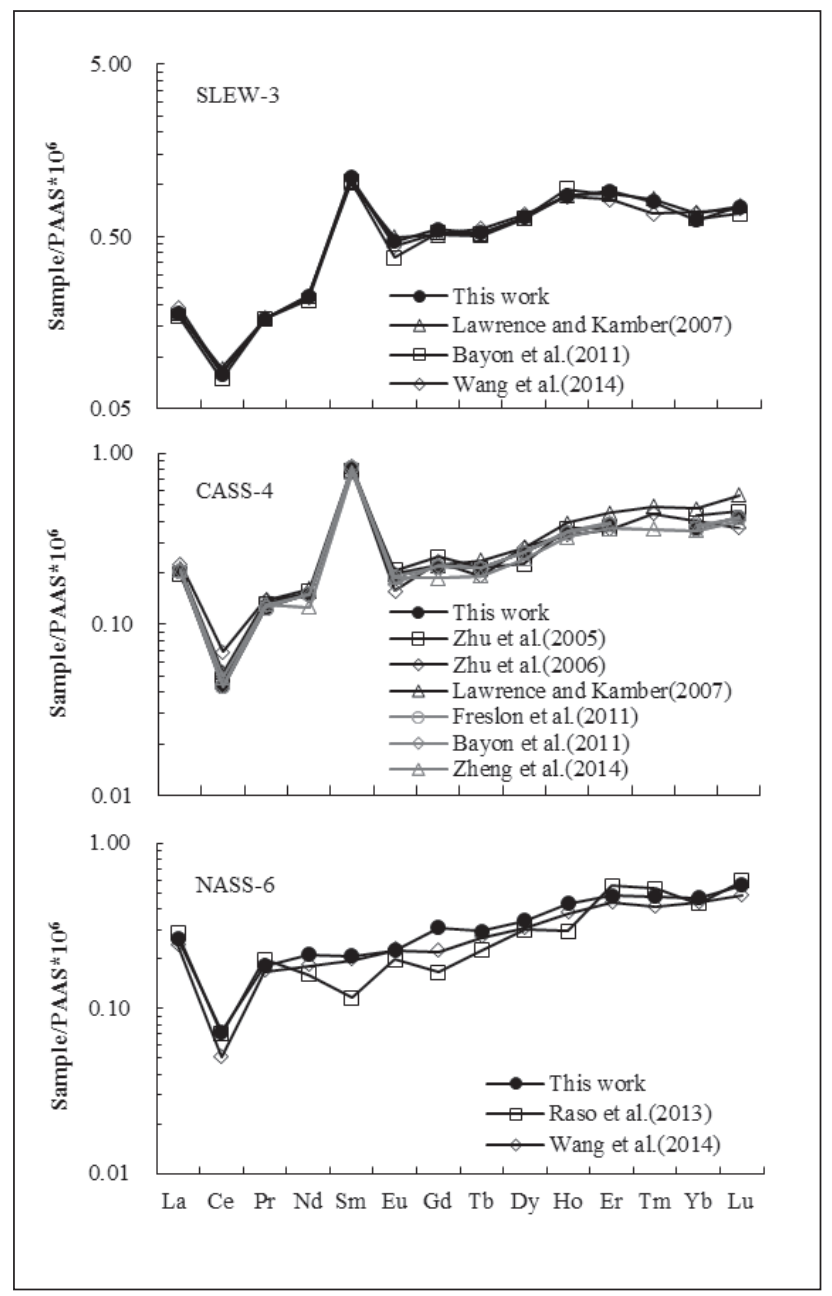

Fig. 2. PAAS normalized REE values of NRC reference materials. were slightly worse than the other recovery values (95\%-100\%) measured by the same research (6) in which REE spikes of $50 \mathrm{ng} / \mathrm{L}$ were added. We conclude that the reasons for the difference of recovery are the statistical limits associated with the low REE concentrations of spikes and samples. Higher spike levels and lower procedural blanks made with ultra-pure water or nitric acid-diluted solution can improve the precision of the method (6) and were used in several studies $(5,19)$. However, the matrix effect on precision was ignored. In fact, for the purpose of clarifying the reasons, the REE recoveries were also measured for SLEW-3 to which $1 \mathrm{ng} / \mathrm{L}$ REE spikes were added. The recovery values ranged from $81.8 \%$ for Sm to $113.3 \%$ for Ho and were worse than those calculated with $10 \mathrm{ng} / \mathrm{L}$ spikes. This confirms the reasons as discussed above.

\section{Application of Method to a Study of the Minjiang Estuary}

The measurement of REE concentrations in estuarine water has been considered a difficult task due to the complex matrix and the dif-

TABLE V

REE Recoveries of NRC Reference Materials

\begin{tabular}{ccccc}
\hline & \multicolumn{4}{c}{ Recovery (\%) } \\
Element & $\mathrm{m} / \mathrm{z}$ & SLEW-3 & CASS-4 & NASS-6 \\
\hline $\mathrm{La}$ & 139 & 105.4 & 111.9 & 103.3 \\
$\mathrm{Ce}$ & 140 & 103.3 & 111.0 & 118.3 \\
$\mathrm{Pr}$ & 141 & 95.3 & 94.9 & 102.5 \\
$\mathrm{Nd}$ & 143 & 98.5 & 105.0 & 95.1 \\
$\mathrm{Sm}$ & 147 & 97.7 & 100.4 & 97.5 \\
$\mathrm{Eu}$ & 153 & 97.5 & 93.0 & 99.9 \\
$\mathrm{Gd}$ & 157 & 100.4 & 91.7 & 98.6 \\
$\mathrm{~Tb}$ & 159 & 92.7 & 94.7 & 100.4 \\
$\mathrm{Dy}$ & 163 & 97.7 & 97.0 & 97.4 \\
$\mathrm{Ho}$ & 165 & 94.1 & 91.6 & 99.6 \\
$\mathrm{Er}$ & 166 & 94.3 & 96.5 & 99.3 \\
$\mathrm{Tm}$ & 169 & 93.5 & 95.2 & 100.9 \\
$\mathrm{Yb}$ & 172 & 97.8 & 92.6 & 97.8 \\
$\mathrm{Lu}$ & 175 & 93.7 & 92.3 & 99.2 \\
\hline
\end{tabular}




\section{Atomic Apectroscopy \\ 1 Vol. 38(4), July/Auust 2017}

TABLE VI

REE Concentrations (ng/L) and PAAS Normalized Ratios of Surface Water From Minjiang Estuary

\begin{tabular}{|c|c|c|c|c|c|c|c|c|c|c|}
\hline & M16 & M17-4 & M18-4 & M19-4 & M20-4 & M21-4 & M23-4 & M26-4 & M27-4 & M28-4 \\
\hline $\mathrm{La}$ & 127.83 & 244.34 & 273.22 & 118.19 & 168.85 & 18.50 & 23.82 & 30.69 & 27.58 & 34.36 \\
\hline $\mathrm{Ce}$ & 188.87 & 389.72 & 479.16 & 216.60 & 215.92 & 30.46 & 28.71 & 46.57 & 32.58 & 55.69 \\
\hline $\operatorname{Pr}$ & 30.02 & 55.26 & 66.86 & 24.81 & 33.44 & 4.24 & 4.78 & 6.73 & 6.36 & 6.93 \\
\hline $\mathrm{Nd}$ & 116.39 & 204.17 & 258.32 & 95.13 & 122.02 & 13.90 & 16.77 & 24.40 & 22.73 & 23.99 \\
\hline $\mathrm{Sm}$ & 24.13 & 39.93 & 50.50 & 17.80 & 24.95 & 3.23 & 4.04 & 5.54 & 4.54 & 5.22 \\
\hline $\mathrm{Eu}$ & 4.23 & 6.42 & 8.90 & 3.26 & 4.52 & 1.02 & 1.38 & 1.64 & 1.33 & 1.55 \\
\hline Gd & 27.34 & 45.12 & 56.13 & 20.11 & 28.63 & 4.58 & 5.43 & 7.37 & 6.29 & 7.47 \\
\hline $\mathrm{Tb}$ & 4.13 & 6.12 & 7.94 & 2.64 & 4.25 & 0.92 & 1.28 & 1.44 & 1.36 & 1.56 \\
\hline Dy & 21.43 & 31.02 & 42.30 & 15.62 & 21.25 & 2.94 & 4.91 & 6.27 & 6.34 & 6.34 \\
\hline Ho & 5.04 & 6.55 & 8.65 & 3.42 & 4.80 & 1.06 & 1.48 & 2.09 & 1.96 & 2.07 \\
\hline $\mathrm{Er}$ & 14.31 & 18.36 & 24.96 & 10.59 & 13.05 & 2.69 & 4.07 & 5.08 & 4.80 & 5.20 \\
\hline $\mathrm{Tm}$ & 2.50 & 3.22 & 4.59 & 1.40 & 2.55 & 0.92 & 1.17 & 1.20 & 1.17 & 1.23 \\
\hline $\mathrm{Yb}$ & 14.76 & 16.24 & 23.33 & 9.36 & 11.49 & 2.77 & 4.14 & 5.19 & 4.86 & 5.33 \\
\hline $\mathrm{Lu}$ & 2.82 & 2.75 & 3.89 & 1.42 & 2.11 & 0.81 & 1.21 & 1.31 & 1.11 & 1.25 \\
\hline $\mathrm{Ce} / \mathrm{Ce}^{*}$ & 0.73 & 0.81 & 0.85 & 0.96 & 0.69 & 0.83 & 0.65 & 0.78 & 0.59 & 0.87 \\
\hline $\mathrm{Eu} / \mathrm{Eu}^{*}$ & 0.91 & 0.86 & 0.94 & 0.99 & 0.94 & 1.38 & 1.44 & 1.33 & 1.26 & 1.27 \\
\hline $\mathrm{Gd} / \mathrm{Gd}^{*}$ & 1.07 & 1.15 & 1.11 & 1.17 & 1.09 & 0.95 & 0.84 & 0.95 & 0.90 & 0.93 \\
\hline
\end{tabular}

ferent extent of matrix effects (7). In order to evaluate the performance of the seaFAST-ICP-MS method on natural waters, especially on the brackish water at various salinities, the brackish river surface water samples collected from the Minjiang Estuary were analyzed to demonstrate the applicability of the entire procedure. Furthermore, for measuring the influence of matrix effects (salinity effects) on REE recovery in seaFAST-ICP-MS, the river surface water samples with various salinities were used. For interpreting the marine geochemistry behaviors of REEs, Ce/Ce*, $\mathrm{Eu} / \mathrm{Eu}^{*}, \mathrm{Gd} / \mathrm{Gd}^{*}$ were calculated following Lawrence and Kamber (31). The elements $\mathrm{Ce}, \mathrm{Eu}$, and $\mathrm{Gd}$ were excluded from the calculation since they can exhibit different oxidation states. Detailed REE concentrations, PAAS normalized values and recoveries are listed in Tables VI and VII.

The REE concentrations and PAAS normalized patterns of surface waters were separated into two groups: the river waters and the brackish waters. The river

TABLE VII

REE Recoveries (\%) of Surface Water From Minjiang Estuary

\begin{tabular}{crrrrrr}
\hline & \multicolumn{5}{c}{ Recovery (\%) } \\
Element & $\mathrm{m} / \mathrm{z}$ & M8-3 & M18-3 & M23-2 & M2-2 & M27-2 \\
\hline La & 139 & 99.5 & 101.6 & 101.2 & 98.8 & 102.1 \\
$\mathrm{Ce}$ & 140 & 104.8 & 100.1 & 100.6 & 101.9 & 99.3 \\
$\mathrm{Pr}$ & 141 & 105.2 & 104.5 & 104.6 & 102.6 & 105.1 \\
$\mathrm{Nd}$ & 143 & 104.8 & 107.4 & 104.0 & 106.4 & 105.6 \\
$\mathrm{Sm}$ & 147 & 104.4 & 105.4 & 105.1 & 102.4 & 103.2 \\
$\mathrm{Eu}$ & 153 & 102.5 & 103.9 & 104.7 & 102.7 & 104.0 \\
$\mathrm{Gd}$ & 157 & 101.6 & 101.2 & 102.6 & 100.4 & 99.8 \\
$\mathrm{~Tb}$ & 159 & 103.2 & 103.0 & 104.1 & 101.9 & 104.3 \\
$\mathrm{Dy}$ & 163 & 101.6 & 102.3 & 102.3 & 99.9 & 100.9 \\
$\mathrm{Ho}$ & 165 & 102.5 & 103.7 & 102.6 & 99.6 & 101.9 \\
$\mathrm{Er}$ & 166 & 101.1 & 102.5 & 102.2 & 97.8 & 102.0 \\
$\mathrm{Tm}$ & 169 & 101.2 & 102.9 & 103.1 & 99.1 & 101.9 \\
Yb & 172 & 101.8 & 100.0 & 103.4 & 100.1 & 101.8 \\
$\mathrm{Lu}$ & 175 & 104.2 & 102.3 & 104.4 & 100.7 & 100.6 \\
\hline
\end{tabular}

waters of M16-M20 had higher concentrations than the HREE-enriched brackish waters from M21 M28 (Figure 3). There was a sharp decrease of REE concentration from the river waters up to $\mathrm{M} 21$, and then rose slightly for the other brackish waters. Besides, the REE normalized patterns of river waters were almost flat, were changed to be HREE-enriched in M21, and then changed to more HREE-enriched in 


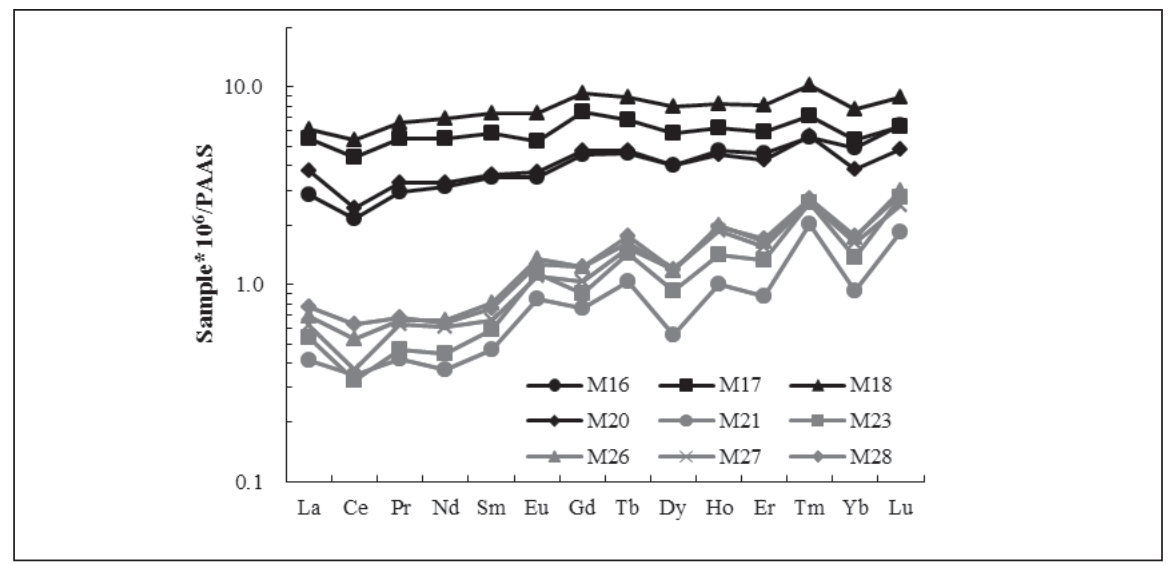

Fig. 3. REE patterns of surface water of Minjiang Estuary.

the other brackish waters. This is due, in part, to the estuarine water which would lead to the removal of the LREEs and a preferential release of the HREEs at the fresh water-seawater interface in the estuary (37-42). Therefore, this results in the seaward decreased REE concentration and increased HREE-enrichment. In addition, the inflow of seawater with low REE concentrations would also dilute the REE concentrations of brackish waters.

Both the river water and brackish water have slightly negative Ce anomalies which are close to the REE character of seawater. The reason of negative Ce anomalies can, therefore, be atrributed to the mixture and dilution of the seawater. Slightly positive Gd anomalies were present in the river waters but not in the brackish waters, probably because Gd anomalies are derived from the widespread anthropogenic application of Gd-chelates in medical imaging which are frequently found in highly populated areas $(12,25) . M 16-M 20$ are located in densely populated areas of the Minjiang River which suggests the reason of Gd anomalies in river waters.

The spike recoveries were determined by REE-spiked brackish water of the Minjiang Estuary. The REE spikes of approximate concentrations (50-500 ng/L) with sample waters were added to the samples of the Minjiang Estuary. The recovery was calculated as the ratio between analyzed and spiked concentrations for each element $(n=3)$. The spike recovery values ranged from 99.5-105.2\% for M8-3 (salinity: 0.1), 100-107.4\% for M18-3 (salinity: 13.4), 100.0-105.1\% for M23-2 (salinity: 23.1), 97.8\%-106.4\% for M2-2 (salinity: 0.1), and from 96.0\%-105.6\% for M27-2 (salinity: 26.0). The spike recoveries of river water samples at different salinities were in similarly close ranges (Table VII).

Since there was no obvious difference in the spike recoveries between samples at distinctive salinities and between light REEs in the same sample, it is believable that the method of seaFAST-ICP-MS used in this work shows excellent performance on the REE measurements of samples at various salinities. Furthermore, the matrix effects are so small that they can be ignored. The highly efficient matrix removal (>99.999\%) obtained by the research of Hathorne et al. (30), in which seaFAST was also used in the preconcentration process, supports the conclusion of the present study. Wang (7) reported the high affinity of Nobias chelate-PA1, which is also used in the seaFAST, and the sufficiently high REE recoveries (> 90\%) when measuring the REEs in the elements and heavy elements of aqueous samples with salinities from $0-35 \%$.

\section{CONCLUSION}

The online preconcentration system coupled with ICP-MS provides a precise and accurate means to obtain quick measurement (8 minutes 48 seconds) of REEs with a small sample volume $(7 \mathrm{~mL})$. To demonstrate the performance of seaFAST-ICP-MS on the analysis of REEs in natural waters, the linearity, blank values, DLs, precision, reproducibility, accuracy, and spike recoveries were analyzed. All of the results show excellent performance of this method. The excellent linearity of the calibration standards ( $R=0.99967-0.99999)$, the low blank values (0.0002-0.426 ng/L) and the DLs (0.007-0.250 ng/L) are applicable for high quality measurement of ultratrace REEs in natural waters. The method was precise and accurate, the precision was estimated to be good $(1.38 \%$ $3.56 \%$ ), and the REE concentrations and PAAS normalized patterns of NRC CRMs measured by this method were comparable with reliable literature values. Furthermore, the spike recovery values of the NRC CRMs were 91.6\%-118.3\%. It is worthy to note that the spike recovery values of estuarine waters at various salinities were also good (96.0\%-107.4\%), suggesting that the matrix effect could be ignored. Successful application of this method for REE measurement in surface water collected from the Minjiang Estuary also validates the ability of performing routine measurement of samples spanning in wide ranges of REE concentrations and salinity.

\section{ACKNOWLEDGMENT}

This work was supported by the National Natural Science Foundation of P.R. China (No. 41376050).

Received September 25, 2016. 


\section{REFERENCES}

1. H. Elderfield, Philosophical Transactions of the Royal Society of Biological Sciences 325, 124 (1988).

2. R. H. Byrne and E. R. Sholkovitz, Handbook on the Physics \& Chemistry of Rare Earths 23, 497 (1996)

3. Y. Nozaki, Encyclopedia of Ocean Sciences 4, 2354 (2001).

4. X. Zheng, Y. Plancherel, M. A. Saito, P. M. Scott, G. M. Henderson, X. Zheng, Y. Plancherel, M. A. Saito, P. M. Scott, and G. M. Henderson, Geochim. Et Cosmochim. Acta 177, 217 (2016).

5. Y. Zhu, A. Itoh, E. Fujimori, T. Umemura, and H. Haraguchi, Journal of Alloys and Compounds 408, 985 (2006).

6. M. Raso, P. Censi and F. Saiano, Talanta 116, 1085 (2013).

7. B. S. Wang, C. P. Lee and T. Y. Ho, Talanta 128, 337 (2014).

8. O. Vicente, A. Padró, L. Martinez, R. Olsina, and E. Marchevsky, Spectrochim. Acta, Part B, At, Spectrosc. 53, 1281 (1998)

9. X. Y. Zheng, J. Yang and G. M. Henderson, Geostandards and Geoanalytical Res. 39, 277 (2015).

10. M. B. Shabani, T. Akagi, H. Shimizu, and A. Masuda, Anal. Chem. (Washington, D.C.); (USA). 62:24, 2709 (1990).

11. J. K. Aggarwal, M. B. Shabani, M. R. Palmer, and K. V. Ragnarsdottir, Anal. Chem. 68, 4418 (1996).

12. M. Bau and P. Dulski, Earth \& Planetary Science Letters. 143, 245 (1996).

13. T. Akagi, K. Fuwa and H. Haraguchi, Anal. Chim. Acta 177, 139 (1985).

14. M. J. Greaves, H. Elderfield and G. P. Klinkhammer, Anal. Chim. Acta 218, 265 (1989)

15. T. J. Shaw, T. Duncan and B. Schnetger, Anal. Chem. 75, 3396 (2003).

16. B. K. Esser, A. Volpe, J. M. Kenneally, and D. K. Smith, Anal. Chem. 66, 1736 (1993).

17. Y. Zhu, A. Itoh, E. Fujimori, T. Umemura, and H. Haraguchi, Bulletin of the Chem. Soc. of Japan 78, 659 (2005).
18. L. Halicz, I. Gavrieli and E. Dorfman, J. Anal. At. Spectrom. 11, 811 (1996).

19. T. Kajiya, M. Aihara and S. Hirata, Spectrochim. Acta, Part B, At. Spectrosc. 59, 543 (2004).

20. S. N. Willie, J. W. H. Lam, L. Yang, and G. Tao, Anal. Chim. Acta 447, 143 (2001).

21. S. Hirata, T. Kajiya, M. Aihara, K. Honda, and O. Shikino, Talanta 58, 1185 (2002).

22. B. S. Garg, R. K. Sharma, N. Bhojak, and S. Mittal, Microchem. Journal 61, 94 (1999)

23. E. K. M. Ueda, P. W. Gout and L. Morganti, J. of Chromatogr. A 988, 1 (2003).

24. M. E. Lagerström, M. P. Field, M. Séguret, L. Fischer, S. Hann, and R. M. Sherrell, Marine Chem. 155, 71 (2013).

25. V. Hatje, K. W. Bruland and A. R. Flegal, Marine Chem. 160, 34 (2014).

26. F. Quéroué, A. Townsend, P. V. D. Merwe, D. Lannuzel, G. Sarthou, E. Bucciarelli, and A. Bowie, Anal. Methods 6, (2014).

27. T. Minami, W. Konagaya, L. Zheng, S. Takano, M. Sasaki, R. Murata, Y. Nakaguchi, and Y. Sohrin, Anal. Chim. Acta 854, 183 (2015).

28. S. N. Willie, Y. Iida and J. W. Mclaren, At. Spectrosc. 19, (1998).

29.S. Poehle, K. Schmidt and A. Koschinsky, Deep Sea Research Part I: Oceanographic Research Papers 98, 83 (2015).

30. E. C. Hathorne, B. Haley, T. Stichel, P. Grasse, M. Zieringer, and M. Frank, Geochem. Geophys. Geosystems. 13, 1 (2012)

31. M. G. Lawrence and B. S. Kamber, Geostandards \& Geoanal. Res. 31, 95 (2007).

32. G. Bayon, D. Birot, C. Bollinger, and J. A. Barrat, Geostandards and Geoanal. Res. 35, 145 (2011).

33. N. Freslon, G. Bayon, D. Birot, C. Bollinger, and J. A. Barrat, Talanta 85, 582 (2011).

34. D. Rahmi, Y. Zhu, E. Fujimori, T. Umemura, and H. Haraguchi Talanta 72, 600 (2007).
35. T. C. C. Rousseau, J. E. Sonke, J. Chmeleff, F. Candaudap, F. Lacan, G. Boaventura, P. Seyler, and C. Jeandel, J. of Anal. At. Spectrom. 28, 573 (2013).

36. K. E. Jarvis, J. G. Williams, E. Alcantara, and J. D. Wills, J. of Anal. At. Spectrom. 11 (1996).

37. J. Hoyle, H. Elderfield, A. Gledhill, and M. Greaves, Geochim. Et Cosmochim. Acta. 48, 143 (1984).

38. E. R. Sholkovitz, Aquatic Geochem. 1, 1 (1995).

39. T. Duncan and T. J. Shaw, Aquatic Geochem. 9, 233 (2003)

40. A. H. Osborne, B. A. Haley, E. C. Hathorne, S. Flögel, and M. Frank, Earth and Planetary Science Letters 406, 174 (2014).

41. M. G. Lawrence and B. S. Kamber, Marine Chem. 100, 147 (2006).

42. S. J. Goldstein and S. B. Jacobsen, Earth \& Planetary Science Letters 89, 35 (1988). 